\title{
The Mysterious Pathologic Process of Autistic Disorder
}

Clyde Sheehan, M.D.

Emory University School of Medicine, Atlanta, Georgia

Follow this and additional works at: https://jdc.jefferson.edu/jeffjpsychiatry

Part of the Psychiatry Commons

Let us know how access to this document benefits you

\section{Recommended Citation}

Sheehan, M.D., Clyde (1992) "The Mysterious Pathologic Process of Autistic Disorder," Jefferson Journal of Psychiatry. Vol. 10 : Iss. 1 , Article 8.

DOI: https://doi.org/10.29046/JJP.010.1.005

Available at: https://jdc.jefferson.edu/jeffjpsychiatry/vol10/iss1/8

This Article is brought to you for free and open access by the Jefferson Digital Commons. The Jefferson Digital Commons is a service of Thomas Jefferson University's Center for Teaching and Learning (CTL). The Commons is a showcase for Jefferson books and journals, peer-reviewed scholarly publications, unique historical collections from the University archives, and teaching tools. The Jefferson Digital Commons allows researchers and interested readers anywhere in the world to learn about and keep up to date with Jefferson scholarship. This article has been accepted for inclusion in Jefferson Journal of Psychiatry by an authorized administrator of the Jefferson Digital Commons. For more information, please contact: JeffersonDigitalCommons@jefferson.edu. 


\title{
The Mysterious Pathologic Process of Autistic Disorder
}

\author{
Clyde Sheehan, M.D.
}

\begin{abstract}
This is a condensed literature review of current etiological and treatment findings in autism. Numerous studies examining autistic individuals for a biological marker have been performed with renewed interest over the past several years. Biochemical studies have revealed excessive amounts of serotonin, dopamine and opiods in many autistics. Reductions in self-injurious behaviors, aggressiveness, hyperactivity and stereotypies in patients on medications targeting these specific receptor sites have been documented. Though genetic studies indicate a significant contribution to the transmission of autism, the final common etiological pathway remains unknown.
\end{abstract}

The term autism was first coined by Bleuler who defined the symptomatology of schizophrenia in the early 1900's, as "divorce from reality (1)." In 1943, Leo Kanner borrowed this term to describe 11 children with puzzling but similar characteristics present since their third birthday, labeling the common syndrome "infantile autism." The salient characteristics of these children include severe language deviations characterized by echolalia and pronoun reversal, repetitive, stereotypic behaviors and inability to relate to people but with strong attachments to objects (2). Kanner's accurate description of this newly discovered syndrome has for the most part stood the test of time with few modifications, and in the DSM III-R bears the name Autistic Disorder (3). However, his speculations regarding other aspects of the condition and possible predisposing factors have been proven largely incorrect. Still a mystery is the nature of the underlying pathologic process of this severely debilitating syndrome, with infrequent concurrence among investigators as to various hypotheses. More questions have been raised due to inconsistent findings in neuropathological and biochemical studies which suggest multiple subtypes of this disorder.

In the past 30 years, research has focused on improving classification of autistic disorder by considering a multiplicity of epidemiological factors. Most researchers attempt to elucidate a common denominator leading to "the [autism] triad" of impaired social, communicative and behavioral skills. Several of these findings have been surprisingly consistent, including a $3-4: 1$ male to female ratio (4), $70-80 \%$ occurrence of mental retardation, primarily in the moderate to severe range, with performance IQ almost invariably greater than verbal IQ $(3,5,6)$, more severe morbidity of female autistic individuals compared to males with autistic disorder (7), and a much greater number of minor physical anomalies compared to normals $(8,9)$. These findings have prompted many unanswered questions, but as in the infancy 
stages of all newly discovered and classified syndromes or disorders, they may aid in the quest for determining a common etiology.

One may ask, "Why express so much concern and exert so much effort in what may be an untreatable and probably irreversible disorder?" First, to give a proper perspective on the magnitude of autistic disorder we should examine its relative prevalence. According to several studies worldwide, autistic disorder occurs at an approximate rate of 4 per 10,000 of the population ages 8 to 12 without discrimination for race or socioeconomic standing (10). For every 25 individuals with schizophrenia or mental retardation there is one individual suffering globally with autistic disorder. Second, due to the pervasive developmental deviations and delays as well as peaks and valleys in various skills, specialized classroom settings serving very few students with much individual attention are necessary for many years. The cost involved in this training process is very high, prohibiting entrance to many autistic children due to lack of funding. Third, of the $15-20 \%$ of autistic individuals who eventually become gainfully employed, there remains the lack of social "know how" and empathy necessary for reciprocal friendships (11). As Leo Kanner has said, "While the schizophrenic tries to solve his problems by stepping out of the world of which he has been a part and with which he has been in touch, [autistic] children gradually compromise by extending cautious feelers into a world in which they have been total strangers from the beginning (2)."

Where should one begin the quest for an explanation of the pathologic process leading to this disorder? The answer to this question will vary considerably as evidenced by the number of possible causes that have been studied. Hypotheses range from the now largely dismissed psychodynamic and analytic to the more quantitative and "hard" variables. The psychodynamic hypotheses suggest that parents of autistic children are often intellectual, socially reserved and emotionally distant, leading to psychosocial deprivation (12). Psychobiological and psychophysiological studies include examination of possible congenital causes, genetic abnormalities, neuropathological findings at autopsy, imaging studies (CT, MRI, PEG, etc.), imbalances in neurotransmitters and abnormalities found in electrophysiological studies (EEG and BAER). Several intriguing findings have been obtained with some degree of consensus. However, due to small populations studied, lack of good technique in some studies, and biases influencing test results, the validity and reliability of many studies are less than desirable. Therefore, in this discussion, more questions will be raised than answered regarding the etiology of this disorder.

How does one explain the overwhelming evidence that autistic disorder tends to select for males 3 and 4 times as often as for females? Also puzzling is a finding that autistic females tend to be more frequently and more severely mentally retarded than affected males. Chromosomal studies have been performed on many autistic subjects in attempts to answer this question as well as to verify a common genetic pathway. A pooled monozygotic (MZ) concordance rate of $64 \%$ and dyzygotic (DZ) concordance rate of $9 \%$ was obtained from three studies incorporating $45 \mathrm{MZ}$ pairs and $36 \mathrm{DZ}$ pairs. These concordance rates relative to the sibling recurrence rate of $3 \%$, strongly indicate a genetic predisposition with a significant environmental 
influence on the development of autism (13). Chromosomal studies have identified deletions, additions, mutations and translocations universally present in numerous other disorders; however, this has not been the case thus far in studies of autistm. Many previously documented chromosomal abnormalities, each with associated clinical findings, e.g., Trisomy-21 (Down's syndrome), fragile X syndrome, XYY syndrome, and XXX syndrome, have been associated with autistic disorder to varying degrees (12). Suggested hypotheses to explain the male overrepresentation in autism have included a multifactorial-polygenic model with different thresholds for males and females, as well as a model where greater etiological heterogeneity exists among male autistic individuals than female autistic individuals. The first hypothesis has been tested, but with equivocal results. The latter hypothesis offers more promise. As studies have shown, approximately $5-12 \%$ of autistic individuals have fragile $\mathrm{X}$ which occurs much more frequently in males than females (14). Utilizing the HardyWeinberg equilibrium and assuming a population prevalence of 3.75/10,000 for autistic males, the expected frequency of affected females is the square of this number of $1.4 \times 10^{-7}$. The observed prevalence in females of approximately $1.25 \times$ $10^{-4}$ is 1,000 times greater than this expected value, thereby nullifying the hypothesis that autism is a strictly X-linked disorder (13). Prenatal and perinatal insults, which occur more frequently in males, may contribute to some cases of autism, especially in the presence of a genetic predisposition (13). Further studies with emphasis on female autistic individuals and their relatives, as well as studies carefully comparing fragile $\mathrm{X}$ patients with autism to those without autism, using linkage studies or chromosomal banding patterns, may provide a clue to the etiology of autism.

Neurological abnormalities have been reported in $30-75 \%$ of autistic individuals in several studies. Typical abnormalities found in this population include hypotonia or hypertonia, clumsiness, choreiform movements, pathologic reflexes, myotonic jerking, drooling, abnormal posture and gait, dystonic posturing of hands or fingers, tremor, ankle clonus, pathologic reflexes, emotional facial paralysis and strabismus (11). Minor physical abnormalities are found much more frequently in autistic children than in their siblings or in age-, sex-, and IQ-matched controls (8). Autistic children with higher numbers of anomalies tend to have lower IQ's, more frequent hospitalizations and less psychiatric and substance abuse family histories compared to autistic children with fewer physical anomalies (9). One study indicated that approximately $25 \%$ of autistic children possess five or more minor physical anomalies, whereas only $3 \%$ of "normal" children and $20 \%$ of "hyperkinetic" children exhibited five or more minor physical anomalies (8). Girls with multiple minor physical anomalies tend to exhibit inhibited behavior and social clumsiness rather than hyperactivity and aggression typically found in boys with similar numbers of anomalies. These neurological signs suggest dysfunction in the basal ganglia, particularly in the neostriatum, as well as closely related structures of the mesial aspect of the frontal lobe or limbic system (15). Some researchers propose that autism results from - injury or dysfunction in bilateral CNS structures including the mesolimbic cortex located in the mesial frontal and temporal lobes, the neostriatum, and the anterior and medial nuclei of the thalamus (15). Therefore, one would hope to uncover 
pathological findings in these three areas of the brain in order to document these clinical findings.

Due to the apparent normal longevity of autistics, systematic autopsy studies of neuropathology are lacking. Autopsies of four patients with autism revealed significant Purkinje cell loss in the cerebella of all four patients (16). Also, a single autopsy of a 29-year-old autistic man in another study revealed major cellular and structural changes in the hippocampus, amygdala and cerebellum, including Purkinje cell loss (17). However, other autopsies of a handful of autistic individuals have been completely unremarkable for neuropathological changes on detailed examination (18). Therefore, viewing the vast spectrum of deviant neurological functioning and the inconsistent findings on autopsy (with the exception of cerebellar Purkinje cell loss and nonspecific ventricular enlargement), we either need to modify our histological techniques for improved resolution or to postulate that the defect lies within the more evasive neurochemical substrates of the brain.

Imaging studies and electrophysiological studies have yielded interesting but inconsistent findings. Computed tomographic (CT) scan studies have demonstrated ventricular enlargement and cerebellar atrophy in approximately $25 \%$ of autistic individuals studied (19). Magnetic resonance imaging (MRI) studies have yielded various findings ranging from hypoplasia of cerebellar vermal lobules VI and VII in 14 of 18 patients in one study (20), to small brain stem size (primarily the pons), and widening of the fourth ventricle in at least two other studies (21). Electroencephalographic (EEG) studies of autistic children suggest that approximately $50 \%$ of these individuals have abnormalities. These abnormalities do not appear to be specific, as focal spike, diffuse spike, slow wave and slow dysrhythmic patterns involving both hemispheres have been documented (22). Unusually low-voltage EEG's have been suggestive of chronic hyperarousal, but these findings have not always been replicated. Epilepsy, which tends to correlate with more severe disease, occurs in approximately $30 \%$ of autistic individuals in adolescence and early adult life compared with $5-14 \%$ experiencing seizures prior to puberty (23).

Biochemical studies in autistics have focused on the indoleamines (serotonin), catecholamines (norepinephrine and dopamine) and endorphins. A well-established finding among several studies is that approximately one-third of autistic individuals have a hyperserotoninemia (24). Blood serotonin levels are significantly higher in autistic children who remain ill compared to those who demonstrate improvement in their symptomatology (25). However, blood serotonin levels do not accurately reflect CNS levels, and increased blood serotonin levels are also found in other childhood psychiatric illnesses. Serotonin blood levels reflect both free and platelet levels of serotonin. Increases in platelet uptake of serotonin may be related to increases in serotonin uptake systems. Clomipramine, which blocks this uptake, has helped some autistics (26). Primarily poor results have been obtained from studies evaluating the effectiveness of fenfluramine, a potent serotonin-depleting agent, but it continues to be used as a research tool (26). Therefore, the role of serotonin in the pathogenesis or as a consequent factor involved in autism remains inconclusive at this time.

Autistic children as a whole have been reported not to differ from other groups 
in cerebral spinal fluid (CSF) levels of homovanillic acid (HVA), the principal dopamine metabolite. However, autistic children with greater locomotor activity and more severe stereotypies tended to have higher CSF levels of HVA (27). In this latter group, neuroleptics, which are dopamine-receptor blocking agents, typically produce significant reduction in hyperactivity, stereotypies, aggression and self-injury as well as enhancing compliance and receptiveness to special education (28). To the contrary, dopamine agonists such as stimulants often cause a worsening of pre-existing stereotypies, aggression and sometimes hyperactivity in autistic children (24). It appears from these data that the dopaminergic system may play an integral role in autistic motor behavior.

Other related biochemical studies have been somewhat less rewarding. Several studies which have examined noradrenergic activity in autistic children list findings from elevation of plasma norepinephrine to reduced plasma 3-methoxy-4-hydroxyphenylglycol, the principal brain metabolite of norepinephrine $(29,30)$. Raised endorphin fraction II levels were found in a study of 29 autistics, correlating to decreased pain sensitivity (31). Autistic children with the highest opioid blood levels exhibit the most pain insensitivity and self-injurious behavior (32). Naltrexone, a potent opiate antagonist, has in at least two studies shown reduction in stereotyped, self-injurious and aggressive behaviors while enhancing social behaviors (32,33). Other studies examining blood adenosine triphosphate and CSF creatine phosphokinase in autistic children have been performed, but overall findings from most of these studies are far from clear and merit further exploration $(34,35)$.

Autism is a behaviorally defined syndrome with multiple etiologies that has been extensively studied and redefined since Leo Kanner's initial description in 1943. Though his depiction of the autistic child's peculiar mannerisms has been minimally modified through the years, his original assumptions regarding etiology have mostly been disproven. Consistent findings among affected individuals are an increased prevalence among males, a significant genetic contribution, an overrepresentation of neurological abnormalities and physical anomalies, cerebellar Purkinje cell loss and ventricular enlargement in some, and hyperserotoninemia in one-third. Treatment with high potency neuroleptics, serotonin uptake blockers, and opiate antagonists has shown improvement in some behaviors, but with significant patient variability. Further research is definitely warranted in the quest for the underlying pathologic process of this devastating disorder, with hopes of improved treatment and possible cure.

\section{REFERENCES}

1. Bleuler E: Dementia praecox or the groups of schizophrenics, 1911. Translated by Zinkin J, New York, International Universities Press, 1950

2. Kanner L: Autistic disturbances of affective contact. Nerv Child 2:217, 1943

3. American Psychiatric Association: Diagnostic and Statistical Manual of Mental Disorders, Third Edition, Revised. Washington, DC, American Psychiatric Association, 33, 1987

4. Tsai LY, Stewart MA, August G: Implication of sex differences in the familial transmission of infantile autism. J Autism Dev Disord 11:165-178, 1981 
5. Ritvo ER, Freeman BJ: Current research in the syndrome of autism: Introduction-The National Society for Autistic Children's definition of the syndrome of autism. J Am Acad Child Psychiatry 17:565-575, 1978

6. Tsai LY: The relationship of handedness to the cognitive, language and visuo-spatial skills of autistic patients. Br J Psychiatry 142:156-162, 1983

7. Wing L: Sex ratios in early childhood autism and related conditions. Psychiatry Research 5:129-137, 1981

8. Gualtieri CT, Alexandra A, Shen D, et al: Minor physical anomalies in alcoholic and schizophrenic adults and hyperactive and autistic children. Am J Psychiatry 139(5):640 642,1982

9. Links P, Stockwell M, Abichandani F, et al: Minor physical anomalies in childhood autism. J Autism Dev Disord 10:273-285, 1980

10. Ritvo E: The UCLA-University of Utah epidemiologic survey of autism: prevalence. Am J Psychiatry 146(2):194-199, 1989

11. Cohen D, Donnellan A, Paul R (ed): Handbook of Autism and Pervasive Developmental Disorders. New York, John Wiley and VH Winston, 1987

12. Kaplan H, Freedman A, Sadock B: Comprehensive Textbook of Psychiatry, Fifth Edition. Baltimore, Williams and Wilkins, 1989

13. Smalley S, Asarnow R, Spence MA: Autism and genetics. Arch Gen Psychiatry 45:953-961, 1988

14. Folstein S, Rutter M: Autism: Familial aggregation and genetic implications. J Autism Dev Disord 18:3-30, 1988

15. Damasio AR, Maurer RG: A neurological model for childhood autism. Arch Neurol 35:777-786, 1978

16. Ritvo ER, Freeman BJ, Scheibel AB, et al: Lower Purkinje cell counts in the cerebella of four autistic subjects: Initial findings of the UCLA-NSAC Autopsy Research Report. Am J Psychiatry 143:862-866, 1986

17. Baumann M, Kemper TL: Histoanatomic observations of the brain in early infantile autism. Neurology 35:866-874, 1985

18. Williams RS, Hauser SL, Purpura DP, et al: Autism and mental retardation. Arch Neurol 37:749-753, 1980

19. Campbell M, Rosenbloom S, Perry R, et al: Computerized axial tomography in young autistic children. Am J Psychiatry 139:510-512, 1982

20. Courchesne E, Yeung-Courchesne R, Press GA, et al: Hypoplasia of cerebellar vermal lobules VI and VII in autism. New England J of Medicine 318:1349-1354, 1988

21. Gaffney GR, Kuperman S, Tsai LY, et al: Morphological evidence for brainstem involvement in infantile autism. Biol Psychiatry 24:578-586, 1988

22. Tsai LY, Tsai MC: Using EEG diagnosis to subtype autistic syndrome. Proceedings, 1984 International Conference of the National Society for Children and Adults with Autism. San Antonio, TX, July, 1984

23. Gillberg C: Autism and pervasive developmental disorders. J Child Psychol Psychiat 31:99-119, 1990

24. Young JG, Kavanagh ME, Anderson GM, et al: Clinical neurochemistry of autism and associated disorders. J Autism Dev Disord 12:147-165, 1982

25. Campbell M, Friedman E, Green WH, et al: Blood serotonin in schizophrenic children. Int Pharmacopsychiatry 10:213-221, 1975

26. Sloman L: Use of medication in pervasive developmental disorders. Psychiatric Clinics of North Am 14:165-182, 1991 
27. Cohen DJ, Caparulo BK, Shaywitz BA, et al: Dopamine and serotonin metabolism in neuropsychiatrically disturbed children: CSF homovanillic acid and 5-hydroxy-indoleacetic acid. Arch Gen Psychiatry 34:545-550, 1977

28. Campbell M: Treatment of childhood and adolescent schizophrenia, in Weiner JM (ed): Psychopharmacology in Childhood and Adolescence. New York, Basic Books, 101-118, 1977

29. Lake CR, Ziegler MG, Murphy DL: Increased norepinephrine levels and decreased DBH in primary autism. Arch Gen Psychiatry 35:553-556, 1977

30. Young JG, Cohen DJ, Caperulo BK, et al: Decreased 24-hour urinary MHPG in childhood autism. Am J Psychiatry 136:1055-1057, 1979

31. Gillberg C: The role of the endogenous opiods in autism and possible relationships to clinical features. In L. Wing (ed), Aspects of Autism: Biological Research, London, Gaskell/The National Autistic Society, 31-37, 1989

32. PankseppJ, Lensing P: Brief Report: A synopsis of an open-trial of naltrexone treatment of autism with four children. J Autism Dev Disord 21:243-249, 1991

33. Campbell M, et al: Naltrexone in autistic children: A double blind and placebo-controlled study. Psychopharmacology Bulletin 26:130-135, 1990

34. Sankar DV: Studies on blood platelets, blood enzymes and leukocyte chromosome breakage in childhood schizophrenia. Behav Neuropsychiatry 2:2-10, 1971

35. Katz RM, Liebman W: Creatine phosphokinase activity in central nervous system disorders and infections. Am J Dis Child 120:543-546, 1970 